\title{
ABORDAGEM SOBRE AS TÉCNICAS CIRÚRGICAS APLICADAS NAS DIFERENTES AFECÇÕES PROSTÁTICAS NO CÃO - REVISÃO
}

\author{
GALVÃo, André Luiz Baptista ${ }^{1}$ \\ HERMETO, Larissa Corrêa ${ }^{2}$ \\ CASTRO, Marines de ${ }^{1}$ \\ VASCONCELLOS, Amanda Leal de ${ }^{1}$ \\ FERREIRA, Guadalupe Sampaio ${ }^{1}$ \\ LÉGA, Elzylene ${ }^{3}$ \\ PINTO, Mildre Loraine ${ }^{4}$
}

RESUMO - A próstata é a única glândula sexual acessória do cão. Dentre as prostatopatias, a hiperplasia prostática benigna, a metaplasia escamosa, as prostatites, os cistos prostáticos, os abscessos e as neoplasias podem estar presentes. O diagnóstico destas afecções baseia-se na sintomatologia, palpação retal, exame radiográfico e ultrassonográfico, assim como exame citológico e histopatológico. O tratamento nas diversas prostatopatias destina-se a reduzir o tamanho prostático, minimizando os sinais clínicos manifestados. No entanto, nem sempre o tratamento clínico é eficaz, desse modo a intervenção cirúrgica se torna medida necessária. Portanto, cada técnica cirúrgica pode ser aplicada isoladamente ou em associação dependendo dos tipos de prostatopatias envolvida. A presente revisão de literatura tem o intuito de apresentar os aspectos anatômicos da glândula e as principais afecções prostáticas no cão adulto, com alternativas em diagnóstico e possibilidades terapêuticas clinico e cirúrgicas para cada afecção.

Palavras-chave: Marsupialização, Omentalização, Orquiectomia, Prostatectomia

\section{APPROACH ON THE SURGICAL TECHNIQUES APPLIED IN DIFFERENT PROSTATIC DISEASE IN DOG - REVIEW}

\begin{abstract}
SUMMARY - The prostate is the only accessory sex gland of the dog. In the midst of prostatopatias, benign prostatic hyperplasia, squamous metaplasia, the prostatitis, prostatic cysts, abscesses and neoplasms may be present. The diagnosis of these disorders based on symptoms, rectal palpation, radiographs and ultraso exam, as well as cytology and histopathology exam. The treatment in several prostatopatias intended to reduce the prostate size, reducing the clinical signs manifested. However, not always the clinical treatment is effective , thus surgical intervention becomes necessary measure. Therefore, each surgical technique can be applied alone or in combination depending on the types of prostatopatias involved. The present literature review aims to present the anatomy aspects of the gland and the major prostatic diseases in the adult dog, with alternative diagnostic and therapeutic possibilities for each clinical and surgical pathology.
\end{abstract}

Keywords: Marsupialization, Omentalization, Orchiectomy, Prostatectomy

\footnotetext{
${ }^{1}$ Pós-graduando em Medicina Veterinária da Faculdade de Ciências Agrárias e Veterinárias, - Universidade Estadual Paulista (FCAV/UNESP) - Jaboticabal-SP

${ }^{2}$ Pós-graduanda em Cirurgia Veterinária da Faculdade de Ciências Agrárias e Veterinárias, - Universidade Estadual Paulista (FCAV/UNESP) - Jaboticabal-SP. Via de Aceso "Prof Dr. Paulo Donato Castellane" Km 05, 14.884-900, Jaboticabal -SP. Brasil.

${ }^{3}$ Docente e Coordenadora do Curso de Graduação em Medicina Veterinária da Faculdade Dr. Francisco Maeda FAFRAM - Fundação Educacional de Ituverava-SP

${ }^{4}$ Docente do Setor de Diagnóstico por Imagem do Centro Universitário Barão de Mauá - Ribeirão Preto-SP
} 


\section{INTRODUÇÃO}

A glândula prostática está presente em todos os mamíferos, sendo mais importante no homem e no cão, devido à assiduidade de moléstias que acometem essas espécies (LEAV; GERALD, 2006). As afecções da próstata atingem cães machos de meia idade a idosos, aparentemente sem predileção racial (BARSANTI; FINCO, 1992). Em meio a as prostatopatias, a hiperplasia prostática benigna (HPB) é a alteração mais comum; cerca de $100 \%$ dos cães não castrados desenvolvem evidências histológicas de hiperplasia com o avançar da idade (CURY et al., 2006). Além da HPB, destacam-se a metaplasia escamosa, as prostatites bacterianas (aguda ou crônica), os cistos prostáticos, os abscessos e as neoplasias. Estas afecções apresentam sinais clínicos semelhantes, devido ao aumento de volume da glândula. Assim, a distinção das afecções prostáticas pela sintomatologia e pelo exame físico não é possível (RUEL et al., 1998).

O diagnóstico das afecções prostáticas é baseado na presença de sinais clínicos, detecção de alterações anatômicas durante a palpação retal, exame radiográfico e ultrassonográfico, como também, na utilização do exame citológico e histopatológico que são considerados importantes métodos no diagnóstico para a distinção das afecções. No entanto, estas afecções podem se apresentar de forma isolada ou concomitante em um mesmo tecido (RUSSO et al., 2009). O cão, similarmente ao homem, é a única espécie que desenvolve espontaneamente a hiperplasia prostática e o adenocarcinoma prostático, com características semelhantes às observadas em humanos (LEAV; GERALD, 2006; FORK et al., 2008). Desta forma, o cão tem sido utilizado, extensivamente, como modelo experimental na medicina, contribuindo para avanços na área da urologia humana (FORK et al, 2008).

Em cães, o objetivo do tratamento das diversas prostatopatias, é o de reduzir o tamanho prostático, aliviando os sinais clínicos manifestados, sendo que a orquiectomia bilateral a principal técnica cirúrgica indicada como medida adjuvante no tratamento destas afecções, exceto para nos animais com neoplasia prostática (RAWLINGS, 1998). Assim, o objetivo da presente revisão literária foi apresentar os aspectos anatômicos da glândula e as principais afecções prostáticas no cão adulto, com alternativas em recursos diagnósticos e possibilidades terapêuticas clínica e cirúrgica para cada afecção.

\section{Aspectos anatômicos}

A próstata é a única glândula sexual acessória do cão (MURASHIMA JUNIOR, 2001; THRELFALL, 2008), sendo composta de elementos glandulares e estromais envolvidos por uma cápsula fibromuscular espessa ( VANNUCCHI et al., 1997; THRELFALL, 2008 ), 
estando localizada, predominantemente, no espaço retroperitoneal, caudal à bexiga, ventral ao reto e dorsal à sínfise púbica (SOUZA; TONIOLLO, 2001). Nos cães, a próstata está localizada na cavidade pélvica na puberdade e permanece nesta posição até a idade adulta; quando idosos, a localização da próstata pode ser mais cranial (região pélvica cranial ou abdominal) devido ao seu aumento gradativo (OLSON et al., 1987; SMITH, 2008). A glândula prostática é constituída por um tecido músculo-glandular e seus ductos desembocam na uretra ao longo de toda a sua circunferência (SMITH, 2008; THRELFALL, 2008). Um septo médio divide a glândula em dois lóbulos, que por sua vez, são divididos em vários lóbulos que contêm numerosas glândulas túbulo-alveolares (SMITH, 2008; THRELFALL, 2008). De acordo com Souza e Toniollo (2001), a próstata é caracterizada por áreas glandulares: o corpo glandular (Corpus prostate) e a área disseminada (Pars disseminata). $\mathrm{O}$ corpo glandular é composto por lobos simétricos separados pelo septo médio-dorsal; já a área disseminada está integrada à parede ventral da uretral sendo envolvida pelo músculo uretral. A artéria prostática penetra na glândula dorsolateralmente, originando-se da artéria pudenda interna. A rede venosa é formada pelas veias prostáticas e uretral que desembocam na veia ilíaca. Os vasos linfáticos drenam-se nos linfonodos ilíacos. A inervação da glândula prostática é realizada pelo nervo hipogástrico (controle simpático) e nervo pélvico (controle parassimpático) (SMITH, 2008). A função da próstata é produzir fluido prostático, que é composto por citrato, lactato e colesterol, este fluido corresponde a terceira fração do ejaculado e possui a função de fornecer suporte e transporte para os espermatozóides durante a ejaculação (SMITH, 2008).

\section{Afecções Prostáticas}

\section{Hiperplasia prostática benigna}

A HPB é o aumento do tamanho benigno da próstata, sendo considerada a enfermidade prostática mais comum dos cães machos, não castrados, 95\% dos animais acometidos apresentam mais de 9 anos de idade (BAUZAITE; ANIULIENE, 2003).

A etiologia da HPB não está fundamentada, a idade e os hormônios testiculares parecem estar envolvidos no processo (LEE et al., 1997). Barsanti e Finco (1992) consideram que com o envelhecimento, ocorre um aumento aparente da glândula prostática, devido ao aumento da sensibilidade do tecido prostático a testosterona, uma vez que a secreção de testosterona e dihidrotestoterona (DHT) tendem a diminuir com a idade. A DHT, metabólito ativo da testosterona, regula o crescimento prostático pela ligação com receptores andrógenos nucleares específicos. Mesmo que a testosterona possa também se ligar aos receptores e estimular o crescimento, a DHT é dez vezes mais potente, pois se dissocia do receptor mais 
lentamente (COTRAN et al., 2000). De acordo com Klausner et al. (1994) a próstata canina com HPB não contém mais DHT do que a de cães normais, mas existe aumento no número de receptores para este metabólito. Além disso, Winter et al. (2010) avaliaram a indução da HPB, com o uso concomitante de derivados de estrógeno e testosterona, observando a participação dos receptores de estrógeno no desenvolvimento da HPB induzida. Segundo Klausner et al. (1994), o estrógeno sensibiliza o tecido prostático aos andrógenos e favorece o aumento da formação de DHT na próstata, estimulando o crescimento da musculatura lisa, síntese de colágeno estromal e a metaplasia escamosa do epitélio.

Estudos realizados por Lowseth et al. (1990), verificaram que todos os cães saudáveis estudados possuíam características histológicas de HPB, a partir dos 6 anos de idade, e que não houve relação entre o grau de HPB e os níveis séricos de testosterona, sugerindo que a progressão dessa afecção ocorre gradativamente durante toda a vida do animal. Já Olson et al. (1987) sugeriram que aproximadamente $80 \%$ de cães de meia idade a idosos têm hiperplasia ou hipertrofia prostática e, uma vez que a glândula aumenta, frequentemente assume a posição mais cranial, semelhante aos achados de Cai et al. (2003).

A HPB pode estar presente sem que ocorram sintomas, contudo quando presente, os sinais como tenesmo, gotejamento hemorrágico pelo pênis, hematúria e corrimento uretral transparente podem ocorrer (JOHNSTON et al., 2000). A compressão uretral pela HPB, manifestação comum em humanos, é uma condição rara em cães (FOSTER, 2007). Nos homens, a próstata é fixa entre o púbis e o reto e o crescimento prostático é caracterizado pela proliferação estromal que invade a uretra, comprimindo-a e obstruindo o fluxo urinário. Em cães, a próstata não é fixa, apresenta crescimento exterior e em todas as direções, envolvendo principalmente o tecido glandular (COTRAN et al., 2000).

A próstata acometida por HPB pode apresentar-se, no exame físico simetricamente aumentada, com consistência firme, mas não endurecida, com contorno regular, superfície lisa, móvel e indolor. O exame ultrassonográfico pode confirmar o aumento de tamanho e mostrar as áreas hipoecóicas (caso a hiperplasia cística estiver presente); geralmente observase um aumento prostático simétrico e difuso (PETER et al., 1995). De acordo com Muzzi et al. (1999), o exame citotológico do material aspirado da próstata de cães com HPB, pode revelar uma grande quantidade de células prostáticas justapostas, com citoplasma basófilico, granular e anisocariose. Segundo Shimomura et al. (2009) em seu estudo, não observaram associação entre os exames histopatológicos e citológicos, de tal forma que a utilização do lavado prostático, como método de diagnóstico para HBP no cão não é indicado, quando utilizado de forma isolada. Conforme Muzzi et al. (1999), o diagnóstico definitivo de HPB deve ser obtido através do exame histopatológico. 
A prostatomegalia não é específica para nenhuma categoria de doença prostática em particular, e a HPB pode estar associada a outras afecções prostáticas (FORK et al., 2008).

Entretanto, para os casos de HPB, a castração é o tratamento mais efetivo, resultando na involução de 70\% do aumento prostático (JOHNSTON et al., 2000). Animais assintomáticos não necessitam de terapia, e a castração é o melhor tratamento, pois ela causa involução permanente da próstata dentro de 3 a 12 semanas. Para animais de alto valor genético pode ser indicada a prostatectomia parcial ou terapias clínicas (HEDLUND, 2003).

O tratamento clínico usado para HPB trata-se da estrogenioterapia para reduzir o tamanho prostático, mas este não é recomendado, pois causa infertilidade, metaplasia escamosa, abscedação e anemia aplásica. Os progestágenos (acetato de megestrol, acetato de medoxiprogesterona e acetato de clormadiona) também devem ser evitados, pois podem promover o hipotireoidismo e o Diabetes mellitus (BAMBERG-THALEN; LINDEFORSBERG, 1993).

Nos homens, a finasterida é utilizada no tratamento da HPB, e também é uma opção terapêutica para cães. Este fármaco bloqueia a conversão da testosterona em DHT, promovendo a redução do diâmetro e volume prostático, além de reduzir a concentração sérica de DHT, não promovendo alterações no parênquima testicular (LAROQUE, 2006).

\section{Metaplasia escamosa}

A metaplasia prostática é a transformação do epitélio glandular em epitélio escamoso estratificado, no qual a ceratina é depositada no interior do lúmen (Di SANTIS et al., 2001). Ocorre secundariamente ao hiperestrogenismo exógeno ou endógeno, que causa estase secretória e alteração no epitélio colunar prostático. A principal causa de hiperestrogenismo endógeno é o tumor de células de sertoli (HARGIS e GINN, 2007). A próstata permanece moderadamente aumentada, e outros sinais relacionados às alterações prostáticas podem estar ausentes. Entretanto, sinais clínicos de hiperestrogenismo podem estar associados, tais como prepúcio pendular, alopecia, hiperpigmentação, ginecomastia, além de alterações nos testículos durante a palpação podem ser notadas. No perfil hematológico são descritos trombocitopenia, granulocitose ou granulocitopenia e aplasia de medula óssea (CHUN; GARRET, 2005; HARGIS; GINN, 2007). A orquiectomia é o método terapêutico de eleição para os casos de tumor de células de sertoli, sendo indicado a ablação do escroto (CHUN; GARRET, 2005).

\section{Prostatites}

Segundo Barsanti e Finco (1992), a HPB e outras condições que promovem alteração 
na arquitetura normal da glândula prostática ( metaplasia, neoplasia ou cistos ) predispõem à infecção, por interferirem com as defesas normais do organismo, ou por promoverem um meio ideal para o crescimento de microorganismos. A prostatite é definida como uma infecção da próstata, com ou sem a formação de abscessos.

A prostatite bacteriana afeta principalmente cães adultos e não castrados. A Escherichia coli é o organismo mais frequentemente isolado, porém a infecção por Staphylococcus aureus, Klebsiella spp., Proteus mirabilis, Mycoplasma canis, Pseudômonas aeruginosa, Enterobacter spp, Streptococcus spp., Pasteurella spp., Haemophilus spp. e Brucella canis pode ocorrer. Os microorganismos usualmente envolvidos na prostatite são os mesmos presentes em infecções do trato urinário, o que sugere que a infecção ocorra de forma ascendente. No entanto a contaminação por via hematógena também é possível (JOHNSTON et al., 2000). Enfermidades fúngicas como blastomicose e criptococose, são raros agentes etiológicos de prostatite no cão (SMITH, 2008).

A infecção prostática pode ser aguda ou crônica, sendo a última mais comum. A forma aguda é perceptível através de sinais clínicos como anorexia, depressão, febre, dor abdominal caudal, corrimento uretral, esforço a micção e defecação, andar enrijecido, edema de escroto e prepúcio e polaciúria. O tamanho, a simetria e o contorno da glândula prostática estão normais ou discretamente aumentados (JOHNSTON et al., 2000). Na forma crônica, o tamanho e a forma da glândula prostática dependem da hiperplasia e fibrose concomitantes, porém ela pode se mostrar menos dolorosa à palpação, aumentada de volume e assimétrica (SMITH, 2008).

No exame físico de prostatites, o paciente pode manifestar dor ao toque retal; as alterações observadas no exame radiográfico incluem prostatomegalia, bordas prostáticas irregulares e mineralização do tecido; na ultrassonografia também podem ser observadas estas mesmas alterações radiográficas, como também espaços intraparenquimatosos hiperecóicos e preenchidos de fluido (SMITH, 2008).

Nos exames laboratoriais complementares, podem estar presentes leucocitose neutrofílica com desvido à esquerda, neutrófilos tóxicos e degenerados no hemograma; hematúria, piúria e bacteriúria são comuns na urinálise; elevação das concentrações séricas da fosfatase alcalina, alanina aminotransferase e creatinina também podem estar presentes (SMITH, 2008).

O aumento do número de leucócitos e hemácias é rotineiramente encontrado na avaliação do sêmen em cães com prostatite crônica (SMITH, 2008). No exame do lavado prostático ou citológico pode-se evidenciar grandes quantidades de neutrófilos degenerados com núcleos túrgidos e presença de bactérias livres ou dentro do citoplasma, podendo ser 
encontrado aumento do número de neutrófilos hipersegmentados com cromatina basófilica (picnose) em caso de prostatite não bacteriana (MUZZI et al., 1999).

De acordo com Smith (2008), o tratamento da prostatite bacteriana baseia-se na administração de antibióticos, sendo de difícil cura, devido à dificuldade de penetração do antibiótico no tecido prostático, isto se deve pela diferença de $\mathrm{pH}$ entre o fluido prostático e o sangue. Smith (2008) e Sakamoto et al., (2008) citaram que os antibióticos devem ser selecionados de acordo com a cultura e antibiograma do lavado prostático, bem como, a capacidade de penetração do fármaco de escolha na membrana lipídica do epitélio prostático. A estreptomicina, a sulfa-trimetropim, a enrofloxacina e a clindamicina são fármacos de escolha (SMITH, 2008; SAKAMOTO et al., 2008; SCOOT, 2005). Barsanti e Finco (1992) salientam que o tratamento deve ser contínuo por no mínimo seis semanas, e o fluido prostático e a urinálise devem ser avaliados semanalmente para um melhor acompanhamento.

Segundo Sirinarumitr et al. (2001), a orquiectomia é uma prática recomendada como tratamento coadjuvante para os casos de prostatite.

Conforme Barsanti e Finco (1992), quando a antibioticoterapia aliada à castração não são métodos eficazes. O uso contínuo de antibióticos em baixas doses por período prolongado ou a prostatectomia são as alternativas restantes.

\section{Cistos e abscessos prostáticos}

Os cistos prostáticos podem ser caracterizados como de retenção ou paraprostáticos. Os de retenção ocupam o parênquima e são causados pelo acúmulo de secreções prostáticas dentro do órgão como resultado de obstruções dos ductos (HOFER et al., 1977). Os cistos paraprostáticos não têm comunicação com a prostáta e alguns autores sugerem que sejam resquícios embrionários dos ductos de Müller (BRAY et al., 1997).

O tamanho e a quantidade de cistos podem alterar as dimensões, simetria e textura da glândula prostática. Esse aumento pode causar sintomas semelhantes aos da HBP. A drenagem e a ressecção cirúrgica são práticas recomendadas com ou sem orquiectomia (BARSANTI; FINCO, 1992).

$\mathrm{Na}$ abscedação, a próstata está assimétrica e aumentada. Os sinais, como tenesmo, disúria, dificuldade de locomoção e corrimento uretral serão dependentes do aumento prostático. Caso haja ruptura do abscesso, podem ocorrer dor, febre, êmese e sepse. A ultrassonografia pode revelar áreas hipoecóicas ou anecóicas pequenas ou grandes (PETER et al., 1995). Segundo Smith (2008) o procedimento cirúrgico é a opção terapêutica em cistos e abscessos prostáticos de tamanho médio a grande, são descritas como alternativas: a omentalização, a marsupialização e a colocação de drenos cirúrgicos. Hedlund ( 2003 ) 
recomenda que abscessos ou grandes cistos devam ser drenados. A escolha do procedimento de drenagem depende do tamanho e da localização do abscesso ou cisto, e que a orquiectomia deve ser realizada, pois esta pode reduzir a duração da infecção.

\section{Neoplasias}

A incidência de neoplasias prostáticas no cão é baixa, todavia, as mais observadas são: adenocarcinoma, carcinoma das células de transição, carcinoma das células escamosas, leiomiossarcoma e fibrossarcoma; de forma rara o linfoma também é descrito (LEAV; GERALD, 2006; ASSIN et al., 2008). O cão é a única espécie que não a humana, que desenvolve espontaneamente o câncer de próstata. A maior parte dos tumores prostáticos caninos corresponde a adenocarcioma (SMITH, 2008). Os carcinomas prostáticos são localmente invasivos, e metastatizam cedo nos linfonodos regionais (ilíacos, pélvicos e sublombares), nos pulmões e nos ossos. Eles invadem frequentemente os ossos, a bexiga, o cólon e os tecidos adjacentes por meio de extensão direta. Além disso, outras áreas podem ser alvos de metástase como: fígado, baço, rins, coração e glândulas adrenais. Quando presente no tecido ósseo pode promover dor ou fraturas patológicas (SMITH, 2008).

Neoplasias prostáticas apresentam prognóstico desfavorável e segundo Basinger et al. (2003) pacientes com neoplasias com alto grau de malignidade morrem dentro de três meses após diagnóstico e ou início de tratamento.

O adenocarcinoma prostático parece ser uma desordem mais comum em cães castrados do que inteiros, porém a orquiectomia não parece ser um fator predisponente ao desenvolvimento de neoplasias prostáticas (TESKE et al., 2002). No cão, a relação entre neoplasia e hormônios não está completamente esclarecida, mas estudos realizados por Leav e Gerald (2006) e Chaisiri e Pierrepoint (2006) demonstraram que muitas próstatas com adenocarcinoma também apresentavam áreas de HPB, sugerindo que a neoplasia possa se desenvolver em ambiente de desequilíbrio hormonal. Entretanto, deve haver envolvimento de outros fatores, já que o tumor em cães parece não responder à restrição androgênica, ao contrário do que ocorre com os homens (FORK et al., 2008). Nos homens, as células do câncer prostático são dependentes dos androgênios para sua manutenção, o objetivo das manipulações endócrinas é privar as células da testosterona (FORK et al., 2008). Segundo Costello e Franklin (1994), a prolactina é um hormônio trófico que representa papel importante no desenvolvimento normal e no crescimento da próstata, sendo possível sua ação durante a evolução de neoplasias prostáticas. De acordo com Fernandez et al. (2010), a participação da prolactina no desenvolvimento de neoplasias prostáticas, estaria relacionada a fatores genéticos e a sua interação entre os mecanismos autócrino/parácrino da glândula. 
Obradovich et al. (1987) publicaram dados de 43 cães com carcinoma prostático. Dezenove cães $(44,19 \%)$ tinham sido castrados, pelo menos, três anos antes do desenvolvimento de qualquer doença prostática. Sete tinham sido castrados com menos de 12 meses de idade. Quatorze cães $(32,55 \%)$ foram apresentados como machos inteiros no momento do diagnóstico. Os dez cães restantes $(23,62 \%)$ haviam sido castrados como tratamento para doenças da próstata presuntivo antes do encaminhamento para os autores. Neste estudo, portanto, a castração em qualquer idade, não mostrou nenhum efeito poupador sobre o risco de desenvolvimento do carcinoma prostático no cão. Segundo os autores, estudos em humanos sugerem que as glândulas adrenais e hipófise desempenham um papel importante na doença

Os sinais clínicos de neoplasia prostática podem incluir perda de peso, claudicação ou fraqueza de membros pélvicos, tenesmo, disquezia, retenção ou incontinência urinária, estrangúria, disúria, poliúria, polidipsia, hematúria, edema de membros pélvicos e dores abdominais ou lombares, em caso de metástase podem ocorrer a manifestação de dipsnéia (LEROY et al., 2009).

Durante a palpação retal a glândula pode apresentar-se endurecida e irregular, podendo estar aderida ao canal pélvico (SMITH, 2008). No exame radiográfico, em casos de neoplasia prostática, pode-se evidenciar prostatomegalia, mineralização do tecido prostático, com contorno irregular, linfadenopatia regional e evidências de metástase nos pulmões ou ossos. No exame ultrassonográfico, pode-se notar achados similares ao radiográfico, bem como áreas hiperecóicas. No entanto, para confirmação do diagnóstico, é necessária a punção aspirativa por agulha fina e/ou biopsia, seguida de exame histopatológico (PETER et al., 1995).

O diagnóstico de neoplasia prostática em cães, geralmente ocorre de forma tardia, o que limita as opções de tratamento, bem como o sucesso terapêutico. A radioterapia tem sido empregada na redução do tamanho prostático, no entanto não aumenta a sobrevida destes animais. Em 1987, Turrel publicou um trabalho em que realizou radioterapia com cobalto 60 no transcirúrigico em 10 cães apresentando adenocarcinoma prostático. Cinco cães apresentaram resposta completa ao tratamento, dois animais vieram a óbito, e os outros três cães, os quais já apresentavam metástase obtiveram baixa resposta ao tratamento.

Alguns trabalhos experimentais têm sido realizados com o intuito de descobrir uma terapia efetiva para as neoplasias prostáticas. L'Eplattenier et al. (2007) concluíram que a prostatectomia subcapsular parcial seguido por terapia fotodinâmica intra-operatória da próstata utilizando o ácido 5-aminolevulínico em cães acometidos por carcinoma prostático não foi capaz de atingir a cura, nem evitar a progressão da mesma. 
Protocolos quimioterápicos também não são bem sucedidos no controle da neoplasia prostática em cães (SMITH, 2008). O tratamento cirúrgico (prostatectomia) raramente possui êxito (SMITH, 2008). Desse modo o prognóstico de cães com neoplasia prostática é reservado a mau (CHUN; GARRET, 2005).

\section{Considerações Gerais sobre as Técnicas Cirúrgicas}

Segundo Smith (2008), Sirinarumitr et al. (2001) e Chun e Garret (2005) a orquiectomia trata-se de um procedimento cirúrgico indicado em cães com HPB, cistos prostáticos, abscessos, prostatite e metaplasia prostática. De acordo com Kustritz e Merkel (1998) nos casos de HPB a redução do tamanho da próstata é observado em nove semanas após a castração, podendo reduzir em até 70\%. Segundo Brandão et al. (2006), cães acometidos por HPB, apresentaram uma redução de $81 \%$ do volume prostático 90 dias após a castração, dado esse notado através do acompanhamento ultrassonográfico, demonstrando que a orquiectomia é uma terapia eficiente para a redução do volume prostático. Conforme Smith (2008) a HPB prostática não recidiva em cães orquiectomizados devido baixa concentração de andrógenos no sangue circulante. Ainda de acordo com Sirinarumitr et al. (2001), nos casos de prostatite a orquiectomia é indicada, pois auxilia na redução do tamanho prostático, porém é sugerido a antibioticoterapia prévia para estes casos, cinco dias antes do procedimento cirúrgico. Segundo Parry (2007) a castração de machos nos casos de neoplasias prostáticas, se mostra ineficaz, pois a privação dos andrógenos não contribui para a progressão da doença. Todavia, em casos de neoplasia prostática concomitante com HPB a orquiectomia é benéfica na redução do tamanho prostático (Domingues, 2009).

Conforme Smith (2008) o procedimento cirúrgico é a opção terapêutica em cistos prostáticos de tamanho médio a grande, são descritas como alternativas: a omentalização, a marsupialização e a colocação de drenos cirúrgicos. Segundo Hedlund (1997) a drenagem cirúrgica e a marsupialização são recomendadas para os casos de cistos e abscessos, visto que antibioticoterapia não é totalmente eficaz, entretanto, esse procedimento pode trazer complicações como sepse, choque e peritonite. De acordo com Basinger e Luther (1993) a reabscedação é uma complicação rotineira tanto na marsupialização como na drenagem cirúrgica, ainda, estes procedimentos predispõem o paciente a uma infecção prostática persistente ou a uma infecção ascendente. Além da recorrência, Boothe (2000) afirma que este procedimento, assim como a utilização de drenos, pode originar complicações como incontinência urinária (incidência de 46\%), infecção recorrente do trato urinário (incidência de $30 \%$ ) e formação de fístula uretrocutânea (incidência de 2\%). White (2000), afirmou que a 
omentalização apresenta uma significativa vantagem entre as técnicas, pois geralmente os pacientes recebem alta dentro de 24 horas, e se comparada com outros as outras técnicas de drenagem, o nível de experiência cirúrgica necessária para omentalização é moderada, e rotineriamente apresenta baixa taxa de complicação pós-operatória. Segundo Apparício et al. (2006), a omentalização proporciona um acesso mais adequado e fácil à próstata, reduzindose a manipulação do órgão e, consequentemente, causando o mínimo de lesão nos componentes neurovasculares da glândula. Segundo o mesmo autor, o pós-cirúrgico desta técnica possui uma recuperação mais segura e rápida, em um período de hospitalização menor e, dessa forma, reduzem-se os custos relacionados ao tratamento. De acordo com Freitag (2007) a omentalização contribui na drenagem das secreções remascentes, na drenagem linfática e minimiza o aparecimento de aderências pós-cirurgicas, sendo esta a técnica de eleição para os casos de cistos prostáticos. No entanto de acordo com Domingues (2009) o posicionamento adequado do omento no interior da próstata é extremamente importante na prevenção de recidivas. White e Williams (1995), descreveram um relato em que acompanharam 20 cães apresentando abscedação prostática cujo tratamento foi realizado com omentalização. Observaram que em 19 cães houve total recuperação (nenhum retorno dentro de 12 meses). Um cão apresentou recorrência, o qual foi submetido a aplicação de drenos de Penrose. Segundo os autores, esta técnica foi um meio simples e eficaz no tratamento cirúrgico desta patologia, com exigência mínima de internação pós-operatória do paciente. A freqüência de complicações graves, incluindo incontinência urinária pós-operatória, foi considerada baixa.

Segundo Freitag et al (2007) e Domingues (2009) a prostatectomia parcial apenas é realizada em animais hígidos, podendo ser uma opção nos casos de abscessos, cistos, casos de HPB não responsiva à orquiectomia, como também, esta técnica pode ser utilizada em medida adjuvante na radioterapia nos animais com neoplasia. A prostatectomia total é raramente recomendada segundo Perry (2007), porém, poderá ser uma medida terapêutica aplicada nos casos de neoplasia prostática, quando realizado diagnóstico precoce e com ausência de metástase conforme descrito por Domingues (2009). Além da dificuldade na execução da técnica, complicações pós-cirúrgicas são descritas por Freitag et al (2007) após a prostatectomia total, dentre elas merecem destaque a incontinência urinária, a possibilidade de estenose da uretra no local da anastomose e a de necrose do colo da bexiga. Segundo Fossum et al. (2002) a incontinência urinária é a complicação mais comum da prostatectomia total e subtotal, ocorrendo em $90 \%$ dos cães.

Em estudos realizados em cães acometidos por câncer de prostata Vlasin et al. (2006) submeteu 11 animais a técnica de prostatectomia total intracapsular e outros 10 a técnica de 
prostatectomia total. Os autores observaram naqueles animais submetidos a prostatectomia total intracapsular uma sobrevida de 112 dias em média, contra 19 dias da outra técnica. Complicações como incontinência urinária, dor persistente ou inflamação local foram vistos com menor gravidade no primeiro grupo. L'Eplattenier et al (2006) descreveram a técnica de prostatectomia parcial com a utilização de laser avaliando suas implicações em cães com carcinoma prostático. Com esta técnica não percebeu-se complicações pós-operatórias tais como incontinência urinária, além do que, a sobrevida destes animais foi de 130 dias antes do aparecimento dos sinais clínicos.

Liptak et al. (2004) aplicaram uma técnica de ressecção transuretral por cistoscopia para o tratamento de neoplasias infiltrativas prostáticas. A técnica foi empregada em 3 cães com carcinoma prostático e 3 fêmeas com carcinoma de células de transição da uretra. Os autores observaram como complicações relacionadas com tal técnica infecção do trato urinário, progressão do tumor e metástases por contato em todos os cães.

\section{CONSIDERAÇÕES FINAIS}

As principais prostatopatias se desenvolvem acompanhadas de prostatomegalia, sendo importante a utilização de métodos de diagnósticos por imagem para o estabelecimento de seu desenvolvimento, embora, o diagnóstico preciso geralmente é dependente do exame histopatológico. Entre as afecções prostáticas, a HPB e a neoplasia prostática, merecem destaque, sendo o cão e o homem as espécies mais acometidas. As opções em tratamento cirúrgico se mostram como medidas eficazes isoladas, ou como adjuvantes em determinadas afecções prostáticas, sendo a orquiectomia um procedimento indicado nos casos de HPB, metaplasia, cistos, abscessos e prostatites; ainda, nos casos de cistos prostáticos e abscessos, a drenagem cirúrgica e marsupialização predispõem o paciente a infecções persistentes e secundárias, sendo a omentalização a medida terapêutica cirúrgica mais segura e eficaz, quando bem realizada. Nos casos de neoplasia prostática as opções em tratamento clínico e cirúrgico são pouco eficazes.

\section{REFERÊNCIAS}

APPARÍCIO, M.et al. Omentalização prostática em cães. Brazil Journal Animal Science, v. 43, n. 6, p. 754-761, 2006.

ASSIN, R.et al. Prostate as sole unusal recurrence site of lymphoma in a dog. In Vivo, v. 22, n. 6. p. 755-777, 2008. 
BAMBERG-THALEN, B.; LINDE-FORSBERG, C. Treatment of canine benign prostatic hyperplasia with medroxyprogesterone acetate, Journal American Hospital Association, v. 29, p. 221, 1993.

BARSANTI . J, A.; FINCO, D. R. Moléstias prostáticas do cão. In: Ettinger, S. J. Tratado de Medicina Interna Veterinária, 3ed. São Paulo: Manole, 1992, p. 941-963.

BASINGER, R.R.; LUTHER, P.B. Prostatic disease. In: BOJRAB, M. J. Disease mechanisms in small animal surgery. 2. ed. Philadelphia: Lea \& Febiger, 1993, p. 539-544.

BASINGER, R. R.; ROBINETTE, C. L. ; SPAULDING, K. A. Prostate. In: SLATTER D. S.; SAUNDERS,W. B. Textbook of Small Animal Surgery. 3.ed. Philadelphia, USA. 2003, p. 1542-1557.

BAUZAITE, N.; ANIULIENE, A. Enlarged prostate lesions of purê-bred and mongrel dogs. Medycyna Weterynaryjna, v. 59, n. 5, p. 686-690, 2003.

BOOTHE, H.W. Prostatic surgery. In: Saunders Manual of Small Animal Practice. 2. ed. Philadelphia:Saunders Company, 2000, p. 1091-94.

BRANDÃO, C. V. S.et al. Orquiectomia para a redução do volume prostático estudo experimental em cães. Archives of Veterinary Science, v. 11, n. 2. p. 7-9, 2006.

BRAY, J. P.; WHITE, R. A. S.; WILLIANS, J. M. Partial resection and omentalization: a new technique for management of prostatic retention cystis in dogs. Veterinary Surgery, v. 26, n. 3, p. 202-209, 1997.

CAI, R. F.et al. Experimental research on spontaneous benign prostate hyperplasia in old dogs. Zhonghua Man Ki Xue, v. 9, n. 9, p. 651-653, 2003.

CHAISIRI, N.; PIERREPOINT, C. G. Examination of the distribuition of oestrogen receptor between the stromal and epithelial compartments of the canine prostate. The prostate. v. $1, \mathrm{n}$. 3, p. 357-366, 2006.

CHUN R.; GARRET, L. Urogenital and Mammary Gland Tumors. In: ETTINGER, S. J.; FELDMAN, E. C. Textbook of Veterinary Internal Medicine. 6ed, St. Louis: Elsevier, 2005, cap. 188, p. 786-787.

COSTELlO, L. C.; FRANKLIN, R. B. Effect of prolactin on the prostate. The Prostate, v. 24, n. 4, p. 162-166, 1994.

COTRAN, R. S.; KUMAR, V.; COLLINS, T. O trato genital masculine. In: ROBBINS. Patologia estrutural e funcional. 6.ed. Rio de Janeiro: Guanabara-Koogan, 2000, p. 919927.

CURY, C. A.; AZOUBEL, R.; BATIGALLA, F. Bladder drainage and glandular epithelial morphometry of the prostate in benign prostatic hyperplasia with sereve symptoms. Instítuto Brasileiro de Urologia, v. 32, p. 211-215, 2006.

Di SANTIS, G. W.; Amorim, R. L.; Bandarra, E. P. Aspectos clínicos e morfológicos das alterações prostáticas em cães - revisão. Revista de Educação Continuada do CRMV-SP, v. 4, f. 2, p. 46-52, 2001. 
DOMINGUES, S. B. Patologia prostática em canídeos: prevalência, sintomatologia e tratamento. 105f. 2009. Dissertação de Mestrado em Medicina Veterinária Faculdade de Medicina Veterinária. Universidade Técnica de Lisboa

FERNANDEZ, I.; TUARINE, P.; GOFFIN, V. Prolactin and human tumorogenesis. Journal of Neuroendocrinology, v. 22, n. 6, p. 2-14, 2010.

FORK, M. A.et al. Establishing an in vivo model canine prostate carcinoma using the new cell line CT 1258. BMC Cancer, v. 15, n. 8, p. 240, 2008.

FOSTER, R. A. In: McGAVIN M. D.; ZACHARY, F. J. Pathology basis of veterinary disease. 4ed. Sta. Louis: Elsevier, cap. 19, 2007, p.1340.

FOSSUM T. W et al. Parte II - Cirurgia de tecidos moles. In: FOSSUM T. W. et al. Cirurgia de pequenos animais. Roca: São Paulo, 2002, p. 892-917.

FREITAG, T.et al. Surgical management of common canine prostatic conditions.

Compendium Continuing Education for Veterinarians, v. 29, n. 11, p. 658-663, 2007.

HARGIS, A. M.; GINN P. E. Male Reproductive System. In: Mc GAVIN; ZACHARY, J. F. Pathology of Veterinary Disease, 4 ed., St Louis: Elsevier, 2007, cap. 17, p. 1223.

HEDLUND, C. S. In: FOSSUN, T. W. et al. Small Animal Surgery, Saint Loius: Mosby, Inc., 1997, cap. 23, p. 553-557.

HOFER, R. W.; DYKES, N. L. ; GREINER, T. P. Marsupialization as treatment for prostatic disease. The Journal of the American Animal Hospital Association, v. 13, n. 5, p. 98-104, 1977.

JOHNSTON, S. D.et al. Prostatic disorders in the dog. Animal Reproduction Science, v. 60, n. 61, p. 405-415, 2000.

KLAUSNER, J. S.et al. Recent developments in the diagnosis and treatment of HPB and prostatic carcinoma. AMERICAN COLLEGE OF VETERINARY INTERNAL MEDICINE. Proceedings... p. 547-548, 1994.

KUSTRITZ, M. V. R.; MERKEL, L. Theriogenology question of the month. Bening prostatit hypertrophy (BPH), prostatitis, and prostatic neoplasia. Journal of American Veterinary Medicine Association, v. 213, n.6, p. 807-809, 1998.

LAROQUE, A. P.et al. Effects of chronic oral administration of a selective $5 \alpha$-reductase inhibitor, finasteride, on the dog prostate, Journal of American Veterinary Medicine Association v. 240, n. 2. p. 93-100, 2006.

LEAV I.; GERALD, V. L. Adenocarcinoma of the canine prostate. Cancer, v. 22, n. 6, p. 1329-1345, 2006.

LEE, C.; KOZLOWSKI, J. L.; GRAYHACK, J. T. Intrinsic and extrinsic factors controlling benign prostatic growth. The Prostate, v. 31, n. 2, p. 131-138, 1997.

LEROY, B. E.; NORTHREP, N. Prostate cancer in dogs: comparatibe and clinical aspects. Journal Veterinary, v. 180, n. 2, p. 162, 2009. 
LIPTAK, J.M. et al. Transurethral Resection in the Management of Urethral and Prostatic Neoplasia in 6 Dogs. Veterinary Surgery, 33, 505-516, 2004.

L'EPLATTENIER, H. F.et al. Partial Prostatectomy Using Nd:YAG Laser for Management of Canine Prostate Carcinoma. Veterinary Surgery, 35:406-411, 2006.

LOWSETH, L. A.et al. Age-related changes in the prostate and tests of the beagle dog. Veterinary Pathology, v. 27, p. 347-353, 1990.

L'EPLATTENIER, H.F.et al. Preliminary results of intraoperative photodynamic therapy with5-aminolevulinic acid in dogs with prostate carcinoma. The Veterinary Journal, p.178, 202-207, 2008.

MURASHIMA JUNIOR, J. C. Mensuração da prostate por ultra-sonografia transabdominal e sua associação com a massa corpórea de cães adultos e clinicamente sadios. 2001. 47f. Dissertação (Mestrado). Faculdade de Medicina Veterinária e Zootecnia, Universidade Estadual Paulista, Botucatu.

MUZZI, L. A. L.et al. Ultra-sonografia e citologia das afecções prostáticas em cães. Arquivo Brasileiro de Medicina Veterinária e Zootecnia, v. 51, p. 9-16, 1999.

OBRADOVICH J.; WALSHAW R.;GOULLAUD. The influence of castration on the development of prostatic carcinoma in the dog. 43 cases (1978-1985). J Vet Intern Med. v.1, n.4, p.183-7,1987.

OLSON, P. N.et al. Disorders of the canine prostate gland: pathogenesis, diagnosis and medical therapy. Compendium Continuing Education Small Animal, v. 09, n. 6, p. 613623, 1987.

PETER, A. T.; STEINER, J. M.; ADMAS, L. G. Diagnosis and medical management of prostate disease in the dog. Seminars in Veterinary Medicine and Surgery (Small Animal), v. 10, n. 1, p. 35-42, 1995.

Parry, N. (2007). The canine prostate gland: part 1 - non-inflammatory diseases. UK Vet Small Animal,v. 12, n. 1, p. 1-5, 2007.

RAWLINGS, C. A. Surgery of the Prostate. In: BOJRAB, M. J. Current Techiques in small animal surgery. 4ed. Maryland: Williams \& Wilkins, 1998, p. 476-487.

RUEL, Y.et al. Ultrasonographic evalution of the prostate in health intact dogs. Veterinary Radiology and Ultrasound, v. 39, n. 3, p. 212-216, 1998.

RUSSO, M.et al. Prostatic perfusion in the dog constrast-enhaced doopler ultrasound. Reproduction in Domestic Animals, v. 2, p. 334-335, 2009, Suplement.

SAKAMOTO, S.et al. Discoespondilite bacteriana associada a prostatite séptica - relato de caso. Veterinária e Zootecnia, v. 15, n. 2, supl. 01, 2008.

SCOOT, A. B. [2005]. Treating UTIs with fluoroquinolones. A case study. Aug.

2005.CLINICAL EDGE. Disponível em:

http://veterinarymedicine.dvm360.com/vetmed/article/articleDetail.jsp?id=179322\&sk=\&date $=\&$ pageID=4 . Acesso em: 4 mar. 2011. 
SHIMOMURA, J. Z.et al. Hiperplasia prostática benigna no cão: comparação entre métodos diagnósticos. Veterinária e Zootecnia, p. 117-126, v. 16, n. 1, 2009.

SIRINARUMITR, K. J.et al. Effects of finateride on size of the prostate gland and semen quality in dogs with benign prostatic hypertrophy. Journal American Veterinary Association, v. 218, p. 1275-1280, 2001.

SMITH, J. Canine prostatic disease: A review of anatomy, pathology, diagnosis and treatment. Theriogenology, v. 71, n. 9, p. 375-383, 2008.

SOUZA, F. F.; TONIOLLO, G. H. Marcadores de tecido prostático no cão. Revista de Educação Continuada do CRMV-SP, v. 4, f.3, p. 63-70, 2001.

TESKE, E.et al. Canine prostate carcinoma: Epidemiologycal evidence of an increased risk in castrated dogs. Molecular and Cellular Endocrinology. v. 197, n. 1-2, p. 251-255, 2002.

THRELFALL, W. Anatomy of the male, female and everthing in between. CVC, Aug. 01, 2008. Disponível em:

http://veterinarycalendar.dvm360.com/avhc/article/articleDetail.jsp?id=568420 . Acesso em: 4 mar. 2011.

TURREL, J.M.; Intraoperative radiotherapy of carcinoma of the prostate gland in ten dogs. J Am Vet Med Assoc. v.190, n.1, p. 48-52, 1987.

VANNUCCHI, C. L.et al. Afecções prostáticas em case: sinais clínicos, diagnóstico e tratamento. Clínica Veterinária, v. 2, n. 11, p. 37-42, 1997.

VLASIN, M.et al. Subtotal intracapsular prostatectomy as a useful treatment for advancedstage prostatic malignancies. Journal of Small Animal Practice, v.47, p. 512-516,2006

WINTER, M. L.et al. Induction of benign prostatic hyperplasia in intact dogs by nearphysiological levels of $5 \alpha$-dihydrotestosrone and 17- $\beta$-estradiol. The Prostate, v. 26; n. 06, p. 325-333, 2010.

WHITE R.A.S.; Prostatic surgery in the dog. Clinical Techniques in SmallAmmal Practice, v.15, N. 1, p. 46-51, 2000.

WHITE R.A.S.; WILLIAMS J.M.; Intracapsular prostatic omentalization: a new technique for management of prostatic abscesses in dogs. Veterinary Surgery, V. 24, n. 5, p. 390-395, 1995. 